\title{
KBG syndrome
}

INSERM

\section{Source}

INSERM. (1999). Orphanet: an online rare disease and orphan drug data base. $\underline{K B G}$

syndrome. ORPHA:2332

KBG syndrome is a rare condition characterised by a typical facial dysmorphism,

macrodontia of the upper central incisors, skeletal (mainly costovertebral) anomalies and developmental delay. 